\title{
Inductive Charging of Ultracapacitor Electric Bus
}

\author{
Paul Griffith, ${ }^{*}$ Dr. J. Ronald Bailey,* Dan Simpson*6
}

\begin{abstract}
Many public transit agencies are exploring ways in which alternative fuels can be utilized to reduce our nation's dependency on imported oil and to avoid the environmental impacts associated with the combustion of petroleum products. Of all the alternative fuel options, electricity is among the most desirable in terms of affordability, availability, security, and sustainability. Unfortunately, limitations in battery technology result in electric vehicle operating ranges that are much lower than those of internal combustion-powered vehicles. Although opportunity charging is one strategy for increasing the driving range of electric buses by means of a series of brief recharges during normally scheduled midday layovers, it has yet to be embraced by the transit industry, in part because of the difficulties involved in having drivers connect and disconnect the bus from the charger at regular intervals throughout the day. Roadway-mounted inductively-coupled power transfer systems effectively remove this constraint by automating the charge process, thereby obviating the need for driver intervention. Ultracapacitor energy storage systems offer advantages over battery systems for such applications.
\end{abstract}

Keywords: Ultracapacitor, Opportunity Charging, Inductive Charging, Transit, Electric Bus.

\section{BACKGROUND}

Battery-electric buses are widely recognized as the most environmentally benign of all the alternativelyfueled public transportation options, even when emissions from the power plants that provide the electricity to recharge the batteries are included in the analysis [1]. This is true of both regulated ("criteria") emissions and greenhouse gas emissions. Electric propulsion is also the only vehicle propulsion technology that can directly utilize clean and renewable energy sources such as solar and wind power. Battery electric buses have additional benefits such as quiet operation and zero tailpipe emissions, highly desirable attributes for urban, campus, and medical center applications involving substantial pedestrian activity and/or noiseand emission-sensitive populations.

In addition to the well-documented environmental benefits, battery electric buses also have lower fuel costs and offer the potential for favorable maintenance costs as compared with diesel and other fuels. A recent Federal Transit Administration report to Congress indicates that battery electric buses require only about one-third the fuel cost per mile than the next cheapest propulsion strategy (catenary electricity for trolley buses), and only about one-quarter the fuel cost as diesel propulsion; even greater fuel cost savings accrue

*Advanced Technologies for Transportation Research Program University of Tennessee at Chattanooga

615 McCallie Avenue, Chattanooga, TN 37403

Fax:+1-423-425-5464 when compared with other alternative fuels [2]. The same study also states that "No fuel considered in this study has lower maintenance costs than diesel . . . Electric-drive buses have fewer drive train and transmission maintenance requirements but may require costly battery replacements. Maintenance costs vary widely for electric drive buses ..." [3].

Given a battery electric bus's favorable environmental benefits, low noise, zero local emissions, low fuel cost, and potential for low maintenance costs, it is somewhat surprising that they have not enjoyed widespread commercialization. Battery electric buses have not been successfully deployed in most applications because the various shortcomings of the battery-electric bus are significant. Virtually all of the associated problems, however, are directly related to deficiencies in battery technology:

1. Low range between recharges;

2. Relatively low battery cycle life expectancy necessitates at least one replacement of the expensive battery system during the service life of the bus;

3. Poor operational reliability of electric buses primarily arises from battery systems being undercharged, out of balance, or containing deteriorated cells that interfere with the proper function of the remaining healthy cells;

4. Substantial maintenance required to keep battery systems in top operational form (e.g., frequent load testing, cell balancing, and cell replacement);
5. Reduced capacity of most battery

chemistries during periods of cold ambient 
temperatures;

6. Inaccurate state-of-charge gauges (imagine driving an automobile containing an undersized fuel tank that did not have an accurate fuel gauge).

Although recent battery developments have produced incremental improvements in battery energy density, thereby enabling modest improvements in vehicle range, such advances have generally come at increased cost and do not remedy the other shortcomings noted above (new concerns have also arisen such as some relating to safety). Modified operational strategies, such as increased frequency inductive charging, can improve daily range capabilities without relying on battery advances. But the disadvantages associated with available and near-term battery technologies persist, representing a considerable impediment to efforts to expand the applicability of battery electric transit.

Aside from batteries, two other electrically rechargeable energy storage systems exist that may have applicability to pure-electric buses: flywheel systems and ultracapacitors. Of these, ultracapacitors are farther along in development with products already having been installed in a number of buses, albeit as components of hybrid-electric and diesel-electric systems rather than in pure-electric buses.

\section{INTRODUCTION TO ULTRACAPACITORS}

Ultracapacitors (also referred to as supercapacitors) are electrochemical capacitors that have unusually high energy densities when compared with common capacitors; they are of particular interest in automotive applications for hybrid vehicles and as supplementary storage for battery electric vehicles [4]. Although they exhibit numerous advantages as compared with traction batteries, their gravimetric energy density is only about $10 \%$ that of lead-acid batteries, heretofore rendering them unsuitable as a primary energy storage element in electric vehicles. A Ragone plot illustrating energy density vs. power density for various energy storage devices is shown in Figure 1 [5].

Energy density, however, may be the only parameter

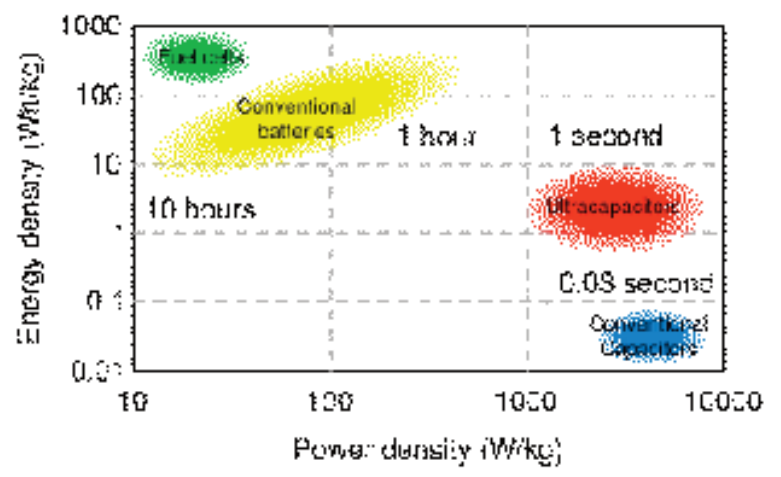

Figure 1. Ragone Plot in which batteries exhibit an advantage over ultracapacitors. Areas of advantage for ultracapacitors as compared with battery systems include the following: 1. Very high rates of charge and discharge resulting in fast recharge times, adequate acceleration power in relatively low energy systems, and excellent acceptance of regenerative braking;

2. Little degradation over hundreds of thousands of cycles resulting in exceptional cycle life;

3. Essentially maintenance-free operation;

4. Excellent reliability over a wide temperature spectrum and harsh environments;

5. Low toxicity of materials used;

6. High cycle efficiency (95\% or higher).

As a result, ultracapacitors would be an excellent substitute for batteries in pure electric vehicles if not for their relatively poor energy density. This sole shortcoming could be circumvented, however, in an application that entailed high frequency, short duration, automated recharging. Certain public transit applications demonstrate favorable operational characteristics, particularly those involving low-speed shuttle operations in which the bus traverses a relatively short loop, returning to the same stops on a frequent, recurring basis. The installation at one of those stops of a roadway-mounted, automatic, inductively-coupled charging station (which does not require driver intervention to accomplish recharge) would complete the essential attributes of a pure electric vehicle system that might effectively utilize ultracapacitors in lieu of batteries for its sole energy storage medium.

\section{ULTRACAPACITORS VS. BATTERIES}

Energy storage characteristics of interest to the electric bus industry include specific energy (the energy capacity of a battery per unit weight), cost, and cycle life. These parameters are summarized in Table 1 for the battery chemistries and ultracapacitors presently in use with (and now under consideration for) electric buses [6].

The reader may note from Table 1 that although ultracapacitors have a high acquisition cost per $\mathrm{kWh}$ of rated capacity as compared with batteries, their extremely long cycle life more than compensates, resulting in relatively low life-cycle costs $(\sim 0.03 / \mathrm{mi}$ as compared with $\sim \$ 0.24 / \mathrm{mi}$ for the low-cost lead-acid battery). Coupled with their high reliability and virtually maintenance-free operation (occasional service only required for the integral cooling fans), an ultracapacitor-powered pure electric bus promises to realize the full cost savings potential of electric buses.

In order to charge a lead-acid battery system at a 60 $\mathrm{kW}$ rate, $60-\mathrm{kWh}$ of capacity is required in order to avoid exceeding the $1 \mathrm{C}$ charge rate [7]. (Fast charging tends to result in accelerated heating of batteries, a 


\begin{tabular}{|c|c|c|c|c|c|}
\hline & Lead-Acid & $\mathrm{Ni}-\mathrm{Cd}$ & Zebra & Li-Ion & Ultracapacitor \\
\hline Specific Energy & $\sim 35 \mathrm{Wh} / \mathrm{kg}$ & $\sim 50 \mathrm{Wh} / \mathrm{kg}$ & $\sim 107 \mathrm{Wh} / \mathrm{kg}$ & $\sim 110 \mathrm{Wh} / \mathrm{kg}$ & $\sim 3 \mathrm{Wh} / \mathrm{kg}$ \\
\hline Acquisition Cost $^{1}$ & $\sim \$ 120 / \mathrm{kWh}$ & $\sim \$ 740 / \mathrm{kWh}$ & $\sim \$ 700 / \mathrm{kWh}$ & $\sim \$ 1,000 / \mathrm{kWh}$ goal & $\sim \$ 33,240 / \mathrm{kWh}$ \\
\hline $\begin{array}{l}\mathrm{Cycle} \mathrm{Life}^{2} \\
\text { (nameplate cycles) }^{3}\end{array}$ & $\sim 500 \mathrm{NPC}$ & $\sim 1,200 \mathrm{NPC}$ & $\sim 1,000 \mathrm{NPC}$ & $>1,000 \mathrm{NPC}$ & $>1,000,000 \mathrm{NPC}$ \\
\hline Battery Life-Cycle Cost ${ }^{4}$ & $\sim \$ 0.24 / \mathrm{mi}$ & $\sim \$ 0.62 / \mathrm{mi}$ & $\sim \$ 0.70 / \mathrm{mi}$ & $\sim \$ 1 / \mathrm{mi}$ goal & $\sim \$ 0.03 / \mathrm{mi}$ \\
\hline
\end{tabular}

Table 1. Battery and Ultracapacitor Comparison

Sources: Exide, Saft, MES-DEA, Santa Barbara MTD, Maxwell

${ }^{1}$ Battery pricing is dependent on volume and currency exchange rates in the case of imported products.

${ }^{2}$ Cycle life based on field experience and is highly dependent on duty cycle, operating temperature, charge profile, maintenance, etc.

${ }^{3}$ Nameplate cycle: The process of one complete or multiple partial discharges of a battery equaling the battery's rated energy (kWh) capacity, and subsequent recharge(s).

${ }^{4}$ Assuming 1.0 DC kWh/mi energy usage rate for a 6.7-m (22-ft) electric bus; excluding differences in maintenance costs.

condition that should be minimized because elevated battery temperature can result in accelerated internal corrosion and decreased battery longevity.) A representative $60-\mathrm{kWh}$ lead-acid battery system has a power rating of approximately $300 \mathrm{~kW}$. By comparison, a $2.6-\mathrm{kWh}$ rated ultracapacitor system has a power rating of approximately $2,700 \mathrm{~kW}$. The nearly ten-fold improvement in power rating attendant to the ultracapacitor system means that frequent recharges can occur without excessive heat generation and that total recovery of regenerative braking energy is possible, unlike with a typical battery system which is estimated to accept only about $50 \%$ of the available regenerative braking energy.

\section{INDUCTIVE CHARGING SYSTEM}

Although opportunity charging is one strategy for increasing the driving range of pure electric buses by means of a series of brief recharges during normally scheduled midday layovers, it has yet to be embraced by the transit industry, in part because of the difficulties involved in having drivers connect and disconnect the bus from the charger at regular intervals throughout the day. An inductively-coupled charging system effectively removes this constraint by automating the charge process, thereby obviating the need for driver intervention.

An inductive charge system is a contactless power transfer system that allows electrical energy to be supplied to buses without any electrical or mechanical contact. Each system consists of two parts (a primary and secondary) that are magnetically coupled similar to a conventional transformer. The primary (stationary) side of a $60-\mathrm{kW}$ system consists of a $70-\mathrm{kW}$ track supply and two $30-\mathrm{kW}$ primary coils imbedded in the street at the opportunity charge station (typically a bus stop at or near the end of the line). The secondary (vehicle) side consists of two $30-\mathrm{kW}$ pickups and rectifiers installed onboard the vehicle. Unlike a conventional transformer, where primary and secondary coils are tightly coupled, the inductive charge system is a loosely coupled system. Power can be transferred across air gaps of several centimeters. Having no physical contact, operation in harsh environments becomes possible. Power transfer is not affected by concrete, asphalt, or other nonpermeable materials.

Major components for a typical $30-\mathrm{kW}$ system are depicted in Figures 2 and 3 . A $60-\mathrm{kW}$ system contemplated for bus applications involves the use of two stationary primary coils and two vehicle-mounted secondary pickups per bus.

When an electric bus pulls into the charging station, the positioning system checks whether the bus is correctly positioned over the charging platform. If proper positioning is confirmed, a signal is sent to the track supply to automatically start the charging process. If the bus is not correctly positioned, the track supply will not switch on. Other objects, such as people, animals, cars, trucks, or other buses cannot cause the activation of the charging station. Termination of the charging process can be executed after a preprogrammed time (e.g., 2 minutes), by the bus driver, or automatically before the bus leaves the charging platform.

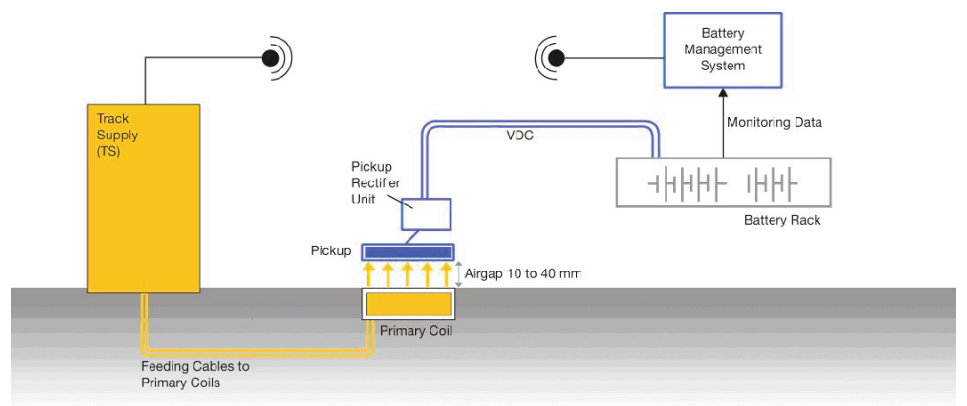

Figure 2. Major Components for Typical 30-kW Inductive Charge System, Block Diagram 


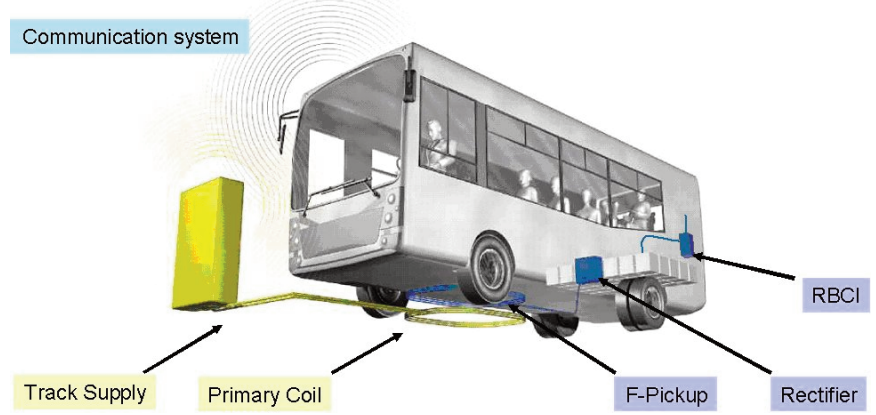

Figure 3. Major Components for Typical 30-kW Inductive Charge System, Installed

\begin{tabular}{|c|c|c|c|c|}
\hline Loop Length & Loop Duration & Energy Use Rate & Energy Used & Charge Time Required $^{1}$ \\
\hline (mi) & $(\mathrm{min})$ & $(\mathrm{kWh} / \mathrm{mi})$ & $(\mathrm{kWh})$ & $(\mathrm{min} \mathrm{sec})$ \\
\hline 1.3 & 9 & 0.95 & 1.24 & $1 \mathrm{~min} 20 \mathrm{sec}$ \\
\hline
\end{tabular}

Table 2. Operating Parameters for 22-ft Electric Bus w/o A/C on Campus Route ${ }^{1}$ Assumes $95 \%$ round-trip energy efficiency through ultracapacitor.

\section{CANDIDATE APPLICATION}

Four candidate electric bus configurations of varying lengths were evaluated for potential deployment on four candidate routes at a major US university campus with respect to the prospects for successful utilization of inductive charge technology [8]. The smaller buses have the lowest energy use requirements and therefore require the least time connected to the charge system to replenish the energy expended during each loop. Although the most promising route has a high energy consumption rate per mile driven because of its high stop-start frequency, its short loop length results in relatively short recharge times required at the end of each loop (less than two minutes for a 22 -ft bus operating without air-conditioning). The operating parameters for a 22 -ft. electric bus running without airconditioning on the most favorable route are presented in Table 2.

It is believed that a 1-minute, 20-second recharge at the conclusion of each nine-minute loop does not represent an unreasonable layover period. Given a nominal 1.24-kWh energy consumption expectation for each loop, an ultracapacitor system with a higher energy capacity is desirable in order to account for normal variations in duty cycle and driver performance, as well as for energy capacity degradation over time. Assuming a 30\% variance between average energy consumption and maximum consumption, and a $20 \%$ capacity loss, an ultracapacitor system with an energy capacity of approximately 1.24 -kWh x $1.3 \times 1.2=1.93$ $\mathrm{kWh}$ would be required. (An additional safety margin is built into the energy use rate estimation because an ultracapacitor-powered bus is expected to have greater regenerative braking energy recovery than the battery buses upon which the empirical data is developed.)

It should be noted that this analysis assumes that only one charging station is installed on the route. If multiple charging stations were deployed it would enable one or more of the following: a longer route, a smaller ultracapacitor system, and/or shorter recharge times at each station.

\section{CANDIDATE ULTRACAPACITOR SYSTEM}

Critical to the success of the contemplated project is the identification of a well-integrated ultracapacitor system. One candidate system would appear to be the Heavy-duty Transportation Module ("HTM") manufactured by Maxwell Technologies. Maxwell's $390 \mathrm{~V}$ HTM module is depicted in Figure 4 and is summarized in Table 3 [9].

In order to achieve the $1.93-\mathrm{kWh}$ deliverable energy requirement identified in the previous section, seven Maxwell 390V HTM modules would be required ( 7 x 282 $\mathrm{Wh}=1.97 \mathrm{kWh}$ ). These seven modules would yield a system mass of $1,155 \mathrm{~kg}(2,541 \mathrm{lbs}$.), or about one-half the weight of a lead-acid battery system of appropriate capacity to accept a $60-\mathrm{kW}$ recurring charge.

Assuming six recharge events per hour (one every ten minutes), ten hours of bus service per day, five days per week, and 50 weeks per year, the ultracapacitor system would experience a total of 15,000 cycles per year. This amounts to approximately 200,000 cycles of the ultracapacitor over a 12-year bus life expectancy, well

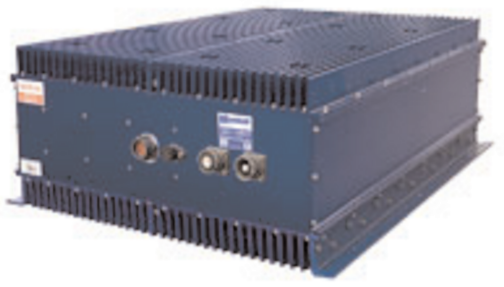

Figure 4. Maxwell 390V HTM Module 


\begin{tabular}{|c|c|}
\hline Nominal Operating Voltage & $390 \mathrm{Vdc}$ \\
\hline Maximum Operating Voltage & $394 \mathrm{Vdc}$ \\
\hline Surge Voltage & $406 \mathrm{Vdc}$ \\
\hline $\begin{array}{l}\text { Energy Available } \\
\text { (to } 1 / 2 \text { nominal voltage) }\end{array}$ & $282 \mathrm{Wh}$ \\
\hline Maximum Continuous Current & $150 \mathrm{~A}$ \\
\hline Maximum Intermittent Current & $950 \mathrm{~A}$ \\
\hline Cycle Life (to 98\% DOD) & $1,000,000$ \\
\hline Operating Temperature Range & $-40 \mathrm{C}$ to $+65 \mathrm{C}(-40 \mathrm{~F}$ to $+117 \mathrm{~F})$ \\
\hline $\begin{array}{l}\text { Maximum Ambient Operating } \\
\text { Temperature }\end{array}$ & $+50 \mathrm{C}(+122 \mathrm{~F})$ \\
\hline Environmental Protection & IP65 (dust tight, water-jet protection) \\
\hline Mass & $165 \mathrm{~kg}(363 \mathrm{lbs})$ \\
\hline $\begin{array}{l}\text { Dimensions } \\
\text { (with fan shroud assembly) }\end{array}$ & $\begin{array}{l}1200 \mathrm{~mm} \text { L x } 740 \mathrm{~mm} \text { W x } 299 \mathrm{~mm} \mathrm{H} \\
(47.3 " \text { x } 29.2 " \text { x } 11.8 \text { ") }\end{array}$ \\
\hline Cost & $\$ 12,500$ \\
\hline
\end{tabular}

Table 3. Maxwell 390V HTM Module

short of the 1,000,000 projected cycle life and suggestive that ultracapacitor reliability would be extremely high during the operational life of the bus.

\section{ACCOMMODATION FOR DEADHEAD TRAVEL}

Although the ultracapacitor system under consideration has adequate energy to propel the bus on the route circuit, it is unlikely that the limited range would be adequate for deadhead travel and/or travel to maintenance facilities. If the vehicle cannot be stored and maintained in close proximity to the route, the range limitation could be overcome through the use of a trailer containing a small battery system. The Santa Barbara MTD has used such a system to power an electric bus between its overnight facility and the route location (Figures 5 and 6). Upon reaching the route, the trailer is uncoupled and the bus performs its service without the trailer; upon conclusion of service, the trailer is again connected to the bus whereupon it powers the bus back to the depot and the batteries in the trailer are recharged in the conventional overnight manner.

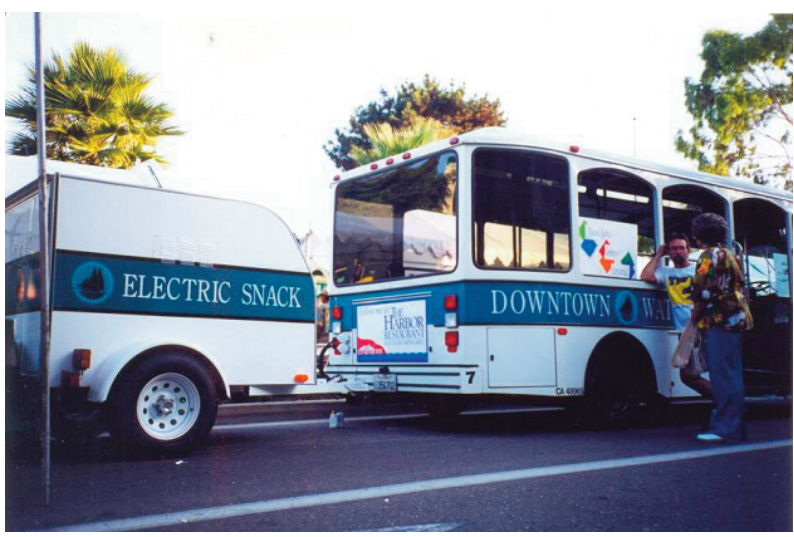

Figures 5 and 6. Battery Trailer - Rear and Front Quarter-Panel Views

\section{SUMMARY AND CONCLUSIONS}

Battery electric buses are widely regarded as the most environmentally benign of all the alternatively-fueled public transportation options, and offer additional benefits such as quiet operation, zero-tailpipe emissions, low fuel costs, and the potential for favorable maintenance costs. They have not, however, enjoyed widespread commercialization because of a number of operational and maintenance shortcomings that are the result of battery technology deficiencies. Although recent battery developments have produced incremental improvements in energy density, high costs and persistent maintenance issues associated with these technologies continue to limit the successful deployment of battery electric buses.

The use of ultracapacitors in lieu of batteries in a pure electric bus would appear to circumvent most of the shortcomings associated with electric buses, namely battery system reliability and battery maintenance requirements. Furthermore, ultracapacitors are more effective at capturing regenerative braking energy, thereby improving the efficiency of the system. The only relative disadvantage of ultracapacitors is their lower

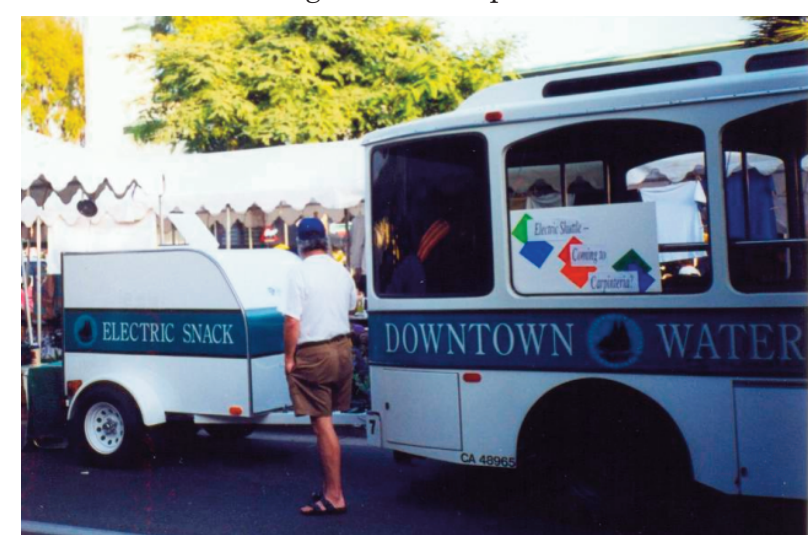

(C) 2008 WEV Journal, pp. $x-x$ 
energy density which results in reduced vehicle range between recharges; this can be mitigated, however, by the use of an automated inductive charging system installed in the roadway at one or more bus stops. If travel to storage or maintenance facilities cannot be accomplished with the ultracapacitor system, a trailermounted battery system could be utilized. In addition to improved vehicle reliability, an ultracapacitor electric bus would have considerably lower life cycle costs than its battery-powered counterpart as a result of reduced maintenance costs and lower energy storage system costs.

\section{REFERENCES}

[1] P. Griffith. Status of U.S. Battery-Electric Bus Operations. Proceedings of Electric Vehicle Symposium 22, Advanced Transportation Technology Institute (ATTI), December 2006.

[2] U.S. Department of Transportation, Federal Transit Administration. Alternative Fuels Study: A Report to Congress on Policy Options for Increasing the Use of Alternative Fuels in Transit Vehicles. December 2006.

[3] Ibid.

[4] http://en.wikipedia.org/wiki/Supercapacitor

[5] Ibid.

[6] Griffith, op. cit.

[7] Approximately five times the overnight rate.

[8] P. Griffith. Preliminary Technical Assessment of Inductively Charged Electric Bus for Application at University Campus. Advanced Transportation Technology Institute (ATTI), January 26, 2007.

[9] Maxwell Technologies, Doc. \# 1011285 Rev.2

\section{AUTHORS}

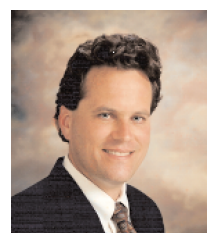

Paul Griffith, National Projects Manager, ATTRP, University of Tennessee at Chattanooga, paul_griffith@verizon.net. Mr. Griffith has spent twenty-seven years in engineering research and development activities with a number of organizations in the transportation and aerospace industries. He was cofounder and President of both the Santa Barbara Electric Transportation Institute and the Santa Barbara Electric Bus Works, and has also worked with the Santa Barbara MTD, Patec Corporation, OerlikonContraves of Switzerland, and General Dynamics Corporation, Convair Division. Mr. Griffith received his Bachelor of Science degree in Mechanical Engineering from the University of California at Santa Barbara. He is past Chair of the National Electric Vehicle Infrastructure Working Council, is the author of numerous technical reports and articles covering electric-bus and other alternative fuel technologies, and holds five U.S. and foreign patents for aerospace products currently under manufacture in Europe.

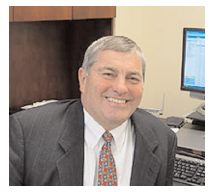
Dr. J. Ronald Bailey is the Guerry Professor in the College of Engineering and Computer Science at the University of Tennessee at Chattanooga. Immediately prior to joining UT Chattanooga, Dr. Bailey served four years as F.W. Olin Professor and Dean of the College of Engineering at Florida Institute of Technology. Dr. Bailey also served as a member of the faculty at N.C. State University for ten years where he taught and served as principal investigator for several research projects. At the University of Texas at Arlington, Dr. Bailey served as Head of the Mechanical \& Aerospace Engineering, Dean of the College of Engineering and Vice President for four years. Dr. Bailey's experience in the private sector is highlighted by his twelve years with IBM Corporation where he held a number of engineering and management positions, each with increasing responsibility, culminating in the position of product manager for the Industrial Sector Division's Boca Raton Development Laboratory. Dr. Bailey earned bachelors and master's degrees in engineering from North Carolina State University where he was inducted into the honorary societies of Pi Tau Sigma, Tau Beta Pi, and Phi Kappi Phi. He earned a Ph.D. from the Institute for Sound and Vibration Research at the University of Southampton, England.

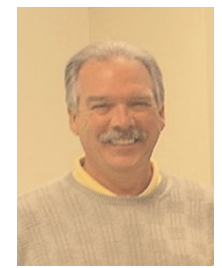

Dan Simpson serves as the Chief Research Scientist with the Advanced Technologies for Transportation Research Program (ATTRP) at the University of Tennessee at Chattanooga (UTC). Previously, Mr. Simpson held the position of Director of Laboratories at the Florida Institute of Technology where he was responsible for managing multiple budgets, a technical services group, engineering projects, technical operations and technical support for 160 Laboratories, including the university machine shop and electronic services. Mr. Simpson also has 10 years of professional engineering and management experience as a manufacturing, project, industrial, and design engineer in the aerospace industry working for Boeing, Martin Marietta, NASA and Delevan Gas Turbine products. Mr. Simpson has an undergraduate degree in Industrial Technology from the University of Idaho and continuing professional education with a number of universities, colleges, private businesses and the military. 
ISSN 2032-6653

\section{Page 0035}


ISSN 2032-6653 
ISSN 2032-6653 